\title{
Histone H3 Lys 4 methylation: caught in a bind?
}

\author{
Robert J. Sims III ${ }^{1}$ and Danny Reinberg ${ }^{1,2,3}$ \\ ${ }^{1}$ Division of Nucleic Acids Enzymology, Department of Biochemistry, Robert Wood Johnson Medical School, \\ Piscataway, New Jersey 08854, USA; ${ }^{2}$ Howard Hughes Medical Institute, Robert Wood Johnson Medical School, Piscataway, \\ New Jersey 08854, USA
}

The $\mathrm{N}$ termini of nucleosomal histone polypeptides are both highly accessible and extensively modified by various chemical moieties. Interpreting the language of these altered amino acids has evolved into an important area of research. The enzymes that catalyze histone modifications have intimate connections to gene expression. Once it was proposed that these modifications may, in fact, represent a combinatorial "histone code" with distinct instructions pertinent for gene expression (Strahl and Allis 2000; Turner 2000), a rush to better understand chromatin biology ensued. Histone lysine methylation has received considerable attention, in part due to its apparent stability (Bannister et al. 2002), its correlation with disease (Schneider et al. 2002) and cellular identity (Trojer and Reinberg 2006), and the discovery that chromatin domains representing a specific activation state correlate with distinct methylated lysine residues (Sims et al. 2003).

Lysine methylation can exist in three different states, monomethylated (me1), dimethylated (me2), and trimethylated (me3). Intriguingly, studies have indicated that the extent of lysine methylation may be differentially "read" by effector proteins, lending credence to the concept of a histone code. However, despite considerable efforts, the downstream, functional (mechanistic) outcomes of histone lysine methylation remain poorly understood. Generally, transcriptionally silent regions contain H3K9me3 (trimethyl), H3K27me2/3 (di- and trimethyl), and H4K20mel (monomethyl), whereas active genes correlate with $\mathrm{H} 3 \mathrm{~K} 4 \mathrm{me} 2 / 3$ (di- and trimethyl), H3K36me2/3 (di- and trimethyl), and H3K79me2 (dimethyl) (Sims et al. 2003; Margueron et al. 2005; Martin and Zhang 2005). The first proteins demonstrated to directly and specifically interact with methylated histone lysines were associated with the repressive marks H3K9me2/3 and H3K27me2/3. Consistent with this, the downstream consequence of $\mathrm{H} 3 \mathrm{~K} 9 \mathrm{me}$ and $\mathrm{H} 3 \mathrm{~K} 27 \mathrm{me}$ recognition is typically considered transcriptional silencing.

The recruitment of effector molecules to histone tails

${ }^{3}$ Corresponding author.

E-MAIL reinbedf@umdnj.edu; FAX (732) 235-5294.

Article is online at http://www.genesdev.org/cgi/doi/10.1101/gad.1468206. is a suitable working model to explain our current functional understanding of histone lysine methylation. If histone methyl marks associated with silent genes are thought to result in chromatin that is refractory to gene expression, what then are the expectations for histone methyl marks associated with active transcription? The simplest prediction suggests that active marks would merely facilitate the opening of chromatin structure to initiate transcription. However, studies over the past year have hinted at a more complex and dynamic process. These studies have identified a collection of proteins that have been reported to selectively recognize diand trimethyl H3K4, marks that are associated with actively transcribed genes. The findings in these studies are in some instances controversial and not always in agreement with previously published work. In this essay, we attempt to reconcile some of these inconsistencies and offer a framework for future experimentation that is consistent with all of the published data. As discussed below, several issues are difficult to reconcile. This raises questions we think worthy of consideration in tackling the aspects of chromatin implicated in gene activation. At the heart of this discussion lies the following question: What is the functional significance of H3K4me2/3 binding, and how does this mechanistically facilitate active transcription?

Both $\mathrm{H} 3 \mathrm{~K} 4 \mathrm{me} 2$ and $\mathrm{H} 3 \mathrm{~K} 4 \mathrm{me} 3$ are found predominantly on active loci, although H3K4me3 occurs concomitantly with active transcription, while H3K4me2 can be present on poised, inactive genes (Schneider et al. 2004; Bernstein et al. 2005). Models have been proposed suggesting that factors selectively "read" H3K4me2 or H3K4me3 (Wysocka et al. 2005, 2006). It may not be necessary to invoke such exclusivity when contemplating the functional impact of these marks. With regard to putative functions, the timeliness and spatial distribution of H3K4 methylation are important contexts to consider. Usually, H3K4me2 and H3K4me3 both peak at the transcription start site. Recent evidence suggests that H3K4me3 occurs after the general transcription machinery assembles on the promoter (Pavri et al. 2006). It also appears that H3K4 methylation does not directly affect transcription per se, signifying the requirement for downstream effectors (Pavri et al. 2006). Consistent with 
this, at least three factors that are associated with transcriptionally active genes have been reported to interact with $\mathrm{H} 3 \mathrm{~K} 4 \mathrm{me} 2 / 3$. These are (1) CHD1, a factor that remodels nucleosomes in an ATP-hydrolysis dependent manner; (2) the multisubunit complex NURF, which, similar to CHD1, mobilizes nucleosomes in an ATP-dependent manner; and (3) WDR5, a polypeptide present in different histone lysine methyltransferase (HKMT) complexes that catalyze H3K4me2/3 (MLL and Set1, among others). The observation that factors known to be involved with active transcription associate with $\mathrm{H} 3 \mathrm{~K} 4 \mathrm{me} 2 / 3$ has important significance for understanding the functional role of this particular histone modification. However, in addition to these proteins implicated in transcriptional activation, the recently identified demethylase JMJD2A and a complex associated with histone deacetylase activity, ING2, proposed to silence active genes, were found to associate with $\mathrm{H} 3 \mathrm{~K} 4 \mathrm{me} 2 / 3$. These observations collectively bring up important issues. Do all nucleosomes within the transcriptionally active unit recruit the same type of factors? Is it possible that a nucleosome simultaneously recruits two different factors, one binding to each of the H3K4me tails? Do the factors that recognize $\mathrm{H} 3 \mathrm{~K} 4 \mathrm{me} 2 / 3$ function in a cascade, such that binding by one factor precedes another? The "readers" of $\mathrm{H} 3 \mathrm{~K} 4 \mathrm{me}$ fall into two categories regardless of gene activity: those that either noncovalently modify or covalently modulate chromatin structure. We begin our discussion with the former, factors that function to remodel nucleosomes in an ATP-dependent manner, CHD1 and NURF.

\section{ATP-dependent chromatin remodeling machines recognize $\mathrm{H} 3 \mathrm{~K} 4 \mathrm{me}$}

One of the first proteins demonstrated to directly associate with methylated H3K4 was human CHD1 (Flanagan et al. 2005; Sims et al. 2005). CHD1 contains a nucleosome-stimulated ATPase, a C-terminal DNAbinding domain, and two tandem chromodomains. The chromodomain is a protein module demonstrated to mediate the methyl-lysine interactions of HP1 and PC, proteins that bind to the repressive $\mathrm{H} 3 \mathrm{~K} 9 \mathrm{me} 2 / 3$ and H3K27me2/3 marks, respectively (Bannister et al. 2001; Lachner et al. 2001; Fischle et al. 2003). Aside from its chromatin remodeling activities, CHD1 functions as a chromatin assembly factor (Lusser et al. 2005) and has physical and functional connections to transcript elongation and termination (Sims et al. 2004). Initially, an interaction between $\mathrm{H} 3 \mathrm{~K} 4 \mathrm{me} 2$ and yeast Chd1 (yChd1) was described based on peptide-affinity precipitation assays using protein fragments of yChd1 (Pray-Grant et al. 2005). We have since learned that alternative methodologies, including two modes of quantitative fluorescence spectroscopy, and structural analyses in yeast did not confirm such an interaction (Flanagan et al. 2005; Sims et al. 2005). Interestingly, subsequent studies using all of the aforementioned methods have indicated that human CHD1 (hCHD1) does, in fact, bind H3K4me2/3 (Flanagan et al. 2005; Sims et al. 2005). Quantitatively, hCHD1 recognizes $\mathrm{H} 3 \mathrm{~K} 4 \mathrm{me} 2$ and $\mathrm{H} 3 \mathrm{~K} 4 \mathrm{me} 3$ with equal affinities ( $5 \mu \mathrm{M})$ (Table 1; Flanagan et al. 2005; Sims et al. 2005). Structurally, hCHD1 requires its tandem chromodomains to recognize the histone tail, although the methyl-lysine is caged within the first chromodomain by two aromatic residues (Flanagan et al. 2005). The use of aromatic residues to cage methyl-ammonium groups is a common structural feature found in many proteins that recognize methylated lysines within histone tails (see below). In contrast to the human protein, one of the critical aromatic residues that cage the H3K4 methyl groups is not present in yChd1, explaining its inability to directly recognize $\mathrm{H} 3 \mathrm{~K} 4 \mathrm{me}$. Some studies do, however, support some involvement of H3K4me in yChd1 functional activities. These include its highly conserved physical interactions with transcript elongation factors and a functional link connecting yChdl with the H3K4me stimulation of the SAGA and SLIK histone acetyltransferase complexes (Pray-Grant et al. 2005). Since yChd1 physically modulates chromatin structure, either these H3K4me effects are indirect or else direct recognition is imparted by an additional factor. As such, other yeast proteins that directly recognize H3K4me have been discovered (see below). In addition, since yeast genes are much shorter than those in higher eukaryotes, yChd1 may be directed to transcribed genes through yChd1-interacting factors making contact with the transcribing machinery. In humans, $\mathrm{H} 3 \mathrm{~K} 4 \mathrm{me} 2 / 3$ may foster CHD1 positioning near the transcription start site directly, which would otherwise be more difficult on genes of such great length.

Aside from hCHD1, the well-characterized chromatin remodeling complex NURF was recently demonstrated to selectively recognize $\mathrm{H} 3 \mathrm{~K} 4 \mathrm{me} 2 / 3$ through its large

Table 1. Comparison of factors reported to bind methylated H3K4

\begin{tabular}{|c|c|c|c|c|c|}
\hline Protein & $\mathrm{H} 3 \mathrm{~K} 4 \mathrm{me} 0$ & $\mathrm{H} 3 \mathrm{~K} 4 \mathrm{me} 1$ & H3K4me2 & H3K4me3 & Reference \\
\hline BPTF & NA & NA & 5 & 2.7 & Li et al. 2006 \\
\hline hCHD1 & NB & $15.1 \pm 5.1$ & $5.0 \pm 1.4$ & $6.1 \pm 1.1$ & Sims et al. 2005 \\
\hline hCHD1 & NB & $\mathbf{1 7} \pm 2$ & NA & $5.2 \pm 0.6$ & Flanagan et al. 2005 \\
\hline ING2 & $2240 \pm 350$ & $208 \pm 80$ & $15 \pm 4$ & $1.5 \pm 1$ & Pena et al. 2006 \\
\hline JMJD2A & NB & NA & NA & 10.4 & Huang et al. 2006 \\
\hline WDR5 & $3.3 \pm 0.3$ & $8.7 \pm 0.3$ & $\mathbf{1 . 0} \pm 0.05$ & $7.8 \pm 0.2$ & Ruthenburg et al. 2006 \\
\hline WDR5 & $\mathbf{6 . 6} \pm 1.3$ & $6.8 \pm 0.1$ & $4.5 \pm 0.2$ & $4.9 \pm 0.3$ & Couture et al. 2006b \\
\hline
\end{tabular}

The equilibrium dissociation constants for the indicated proteins are shown in micromolar concentrations. (NA) Not analyzed; (NB) no binding detected under the conditions tested. Bold indicates comparable equilibrium dissociation constants. 
subunit BPTF (Wysocka et al. 2006). This is an important finding, coupling the modification of histone polypeptides with subsequent recognition by a factor well known to be associated with active transcription. The four-subunit NURF complex has been shown to stimulate transcription by facilitating preinitiation complex formation through the remodeling of nucleosomes within or near the promoter (Mizuguchi et al. 1997). In vivo studies identified many NURF target genes in Drosophila and revealed the critical involvement of NURF during development (Badenhorst et al. 2005). BPTF uses a plant homeodomain (PHD) finger to directly associate with $\mathrm{H} 3 \mathrm{~K} 4 \mathrm{me} / 3$, distinguishing itself from the previously known domains that bind methyl-lysines; that is, the chromodomain and its related protein modules, the Tudor and MBT domains (Maurer-Stroh et al. 2003). The discovery that PHD fingers can recognize methylated lysine residues has important significance (see also the ING [inhibitor of growth] family below), as it expands our catalog of methyl-lysine readers, and since this domain is present in many chromatin-associated proteins, additional methyl-binding proteins will likely be identified. From a structural standpoint, the PHD finger of BPTF recognizes the methyl groups of $\mathrm{H} 3 \mathrm{~K} 4 \mathrm{me} 2 / 3$ through four aromatic residues (Li et al. 2006), in a manner reminiscent of chromodomain recognition of H3K9me2/3, H3K27me2/3, and H3K4me2/3 (Jacobs and Khorasanizadeh 2002; Nielsen et al. 2002; Fischle et al. 2003; Flanagan et al. 2005). Isothermal titration calorimetry was used to quantitatively determine the binding affinities of BPTF to H3K4me3 and H3K4me2, and they were reported to be $\sim 2.7 \mu \mathrm{M}$ and $5.0 \mu \mathrm{M}$, respectively (Li et al. 2006). Peptide affinity precipitation and coimmunoprecipitation assays strongly suggested that BPTF binds with greater preference (or exclusively) to H3K4me3 than to H3K4me2 (Wysocka et al. 2006). However, the calculated equilibrium dissociation constants do not support this notion, and highlight the need to use quantitative methods when examining issues of specificity with respect to methyl recognition. Arguments for specificity are more informative when free energy changes between two states are compared. Using the Kd values provided above, the difference between the changes in free energy is readily calculated. The difference between BPTF binding to $\mathrm{H} 3 \mathrm{~K} 4 \mathrm{me} 2$ versus $\mathrm{H} 3 \mathrm{~K} 4 \mathrm{me} 3$ results in a free energy difference of a fraction of the energy of a single hydrogen bond. As such, this analysis suggests that BPTF recognizes $\mathrm{H} 3 \mathrm{~K} 4 \mathrm{me} 2$ and H3K4me3 with equal affinity. It should be noted that the in vivo experiment suggesting that NURF association with chromatin is in part mediated by $\mathrm{H} 3 \mathrm{~K} 4 \mathrm{me} 3$ used knockdown of WDR5, which affects not only H3K4me3, but also H3K4me1 and H3K4me2 (Wysocka et al. 2005; Dou et al. 2006; A. Shilatifard, pers. comm.). Additional in vivo experimentation should further clarify the issue of H3K4me3 specificity in the future. Specificity aside, the discovery of BPTF as an H3K4me2/3-binding factor provides a key first step toward elucidating the molecular function of $\mathrm{H} 3 \mathrm{~K} 4 \mathrm{me}$ in active transcription.

Chromatin remodeling machines recognize H3K4me2/
3. Yet, we still do not understand if and how this mark facilitates transcriptional activation. A functional role for NURF binding to H3K4me is supported by in vivo experiments (Wysocka et al. 2006), but its mechanistic relevance has yet to be determined. NURF interaction with $\mathrm{H} 3 \mathrm{~K} 4 \mathrm{me} 3$ was proposed to regulate transcription initiation via chromatin remodeling (Wysocka et al. 2006). However, studies using a fully reconstituted transcription system in vitro, together with chromatin immunoprecipitation (ChIP) studies in vivo (Pavri et al. 2006), as well as studies performed in yeast (Dover et al. 2002; Sun and Allis 2002; Henry et al. 2003), demonstrated that the establishment of H3K4 trimethylation itself is dependent on active transcription and $\mathrm{H} 2 \mathrm{~B}$ monoubiquitination; the latter is also a nucleosomal mark set after the onset of transcription (Henry et al. 2003; Pavri et al. 2006). Thus, H3K4me3 occurs post-initiation and after promoter nucleosomes have been cleared or remodeled. In addition, NURF is recruited to promoter regions through interaction with transcriptional activators (Xiao et al. 2001), so its potential recruitment via interaction with $\mathrm{H} 3 \mathrm{~K} 4 \mathrm{me} 2 / 3$ is in need of better clarification. However, if NURF does bind equally well to H3K4me2 and H3K4me3 as indicated by quantitative analyses, and NURF is recruited to promoters by activators, then NURF may be preloaded on some inducible promoters containing H3K4me2 (excluding heat shock) (Smith et al. 2004). Such preloading of NURF (and perhaps hCHD1) may expedite the remodeling activities needed for rapid induction. Consistent with this, NURF has been directly implicated in activation of nuclear hormone-responsive genes (Badenhorst et al. 2005). In the case of noninducible genes, a distinction between H3K4me2 and H3K4me3 may not exist, as single mononucleosome mapping revealed that these marks not only colocalize but were found to occur on the same nucleosome (Kouskouti and Talianidis 2005). The purpose for NURF or hCHD1 recruitment to $\mathrm{H} 3 \mathrm{~K} 4 \mathrm{me} 2 / 3$, which peaks at transcriptional start sites, is unclear as it relates to chromatin remodeling. Is remodeling also required at the promoter for reinitiation? Is there a requirement for remodeling chromatin downstream from the promoter spatially, and if so, what is the purpose? Given that hCHD1 can function as a chromatin assembly factor (Lusser et al. 2005), it may play a role in the maintenance of chromatin structure in the wake of RNAPII, perhaps positioning H3K4me-nucleosomes near the $5^{\prime}$ end of genes (Shilatifard 2006). Analogous to HP1 recruitment, NURF/hCHD1 may recruit additional downstream effectors that facilitate aspects of transcriptional activation. Indeed, this appears to be the case for human CHD1 (R.J. Sims and D. Reinberg, unpubl.).

\section{Enzymes that covalently modify histones recognize H3K4me}

Several proteins that recognize H3K4me are associated with enzymatic processes that either add or remove covalent histone modifications. A great deal of interest has focused on the newly discovered histone demethylases 
(Bannister and Kouzarides 2005; Trojer and Reinberg 2006). The H3K9me3 and H3K36me3 demethylase JMJD2A directly recognizes both $\mathrm{H} 3 \mathrm{~K} 4 \mathrm{me} 2 / 3$ and H4K20me3 via its tandem Tudor domains (Huang et al. 2006; Kim et al. 2006). The structure of the tandem Tudor domains of JMJD2A bound to H3K4me3 reveals a unique interdigitated structure (Huang et al. 2006). Consistent with other methyl-lysine recognition domains, the trimethyl-lysine residue is caged by three aromatic amino acids, one contributed from the first domain and two from the second domain (Huang et al. 2006). In general, the biological significance of JMJD2A binding to $\mathrm{H} 3 \mathrm{~K} 4 \mathrm{me} 3$ is not clear. JMJD2A binding to H4K20me3, a mark associated with both constitutive heterochromatin (Schotta et al. 2004) and DNA damage (Sanders et al. 2004), complicates speculation. Is JMJD2A-mediated removal of $\mathrm{H} 3 \mathrm{~K} 9 \mathrm{me} 3$ and $\mathrm{H} 3 \mathrm{~K} 36 \mathrm{me} 3$ a requirement for proper gene activation or a response to chromatin alteration accompanying DNA damage? Given that H3K4me3 occurs post-initiation, this appears to be a late event and, therefore, JMJD2A activity may be involved in silencing genes upon DNA damage or in attaining a state suitable for repair of loci affected by DNA damage. Additional studies are needed to provide functional context for these findings. However, since research in this area is moving at a rapid pace, answers to the questions raised above are likely to come soon.

The discovery that ING2 directly recognizes H3K4me2/3 may provide the missing functional context toward understanding the biological significance of methyl marks in transcriptional regulation. The ING family of tumor suppressors binds preferentially to H3K4me2 and H3K4me3 via their PHD fingers, similarly to BPTF (Pena et al. 2006; Shi et al. 2006). Importantly, related ING proteins from yeast were shown to bind H3K4me2/3 (Yng1, Yng2, Pho23), pinpointing direct readers of this active mark in Saccharomyces cerevisiae (Pena et al. 2006; Shi et al. 2006). In humans, all five ING proteins (ING1-5) bind selectively to H3K4me2/3 (Kd values 1$10 \mu \mathrm{M})$ (Shi et al. 2006). The binding of ING2 to $\mathrm{H} 3 \mathrm{~K} 4 \mathrm{me} 3$ was proposed to facilitate gene repression during DNA damage, consistent with ING2 association with the mSin3a-HDAC1/2 deacetylase corepressor complex (Shi et al. 2006). These findings are significant for several reasons. First, H3K4me3 can no longer be considered to be a mark for active transcription exclusively. Moreover, it is unsafe to assume distinct functional consequences based on simple correlations of single methyl marks. As such, H3K4me2/3 is differentially interpreted on the same gene dependent on the cellular context (i.e., DNA damage). In addition to the important finding of linking ING2-mSin3a to $\mathrm{H} 3 \mathrm{~K} 4 \mathrm{me} 2 / 3$, this study provides data that methylated $\mathrm{H} 3 \mathrm{~K} 4$ stimulates ING2-associated histone deacetylase activity in vitro (Shi et al. 2006). The notion that histone modifications not only recruit downstream effectors but also stimulate catalytic activities is of great significance. Shi et al. (2006) provide data that ING2 complexes bind exclusively to $\mathrm{H} 3 \mathrm{~K} 4 \mathrm{me} 2 / 3$, but not $\mathrm{H} 3 \mathrm{~K} 4 \mathrm{meO}$ or $\mathrm{H} 3 \mathrm{~K} 4 \mathrm{mel}$ (Shi et al. 2006), results fully supported by quantitative binding analyses (Pena et al. 2006). Unfortunately, a contradictory and confusing issue present in this study is that ING2-associated histone deacetylase activity was stimulated approximately twofold when histone octamers were pretreated by SET7/9 (Shi et al. 2006). However, SET7/9 has been structurally determined to exclusively catalyze H3K4 monomethylation (Xiao et al. 2003; Kouskouti et al. 2004; Couture et al. 2006a). Shi et al. (2006) use antibodies to affirm H3K4 dimethylation by SET7/9 in this assay, but given that antibodies can exhibit cross-reactivity, their use as the only test is not advisable. In this same study, ING2 binding to bulk histones was increased by pretreatment with SET7/9, again raising the issue of the identity of ING2 targets (Shi et al. 2006). Despite this, structural and quantitative binding studies clearly indicate that ING2 selectively recognizes H3K4me2/3 (Pena et al. 2006). Like the chromo-, Tudor, and PHD finger domains described above, the PHD finger of ING2 cages the methyl group by two aromatic residues (Pena et al. 2006), suggesting convergent evolution with respect to methyl recognition.

To complicate matters, mammalian ING proteins associate with both histone acetyltransferase and deacetylase activities (Doyon et al. 2006), although all clearly associate with $\mathrm{H} 3 \mathrm{~K} 4 \mathrm{me} 2 / 3$ (Shi et al. 2006). How are these opposing activities distinguished from one another? In yeast, a similar contradiction occurs as Yng1 and Yng2 associate with HAT complexes (NuA3 or NuA4, respectively) (Nourani et al. 2001; Howe et al. 2002), while Pho23 is associated with HDAC activity (Nourani et al. 2003), despite the fact that each interacts directly with H3K4me2/3 (Shi et al. 2006). Deletion of Set1, the enzyme that catalyzes all levels of H3K4 methylation in yeast, has no effect on the chromatin binding of the Yng1-associated NuA3 HAT complex (Martin et al. 2006). In contrast, deletion of Set2, which catalyzes H3K36 methylation in yeast, significantly reduced NuA3 binding to histones (Martin et al. 2006). A further decrease in histone binding was observed when both Set 1 and Set2 were deleted, but the results clearly indicate that H3K4 methylation alone has no effect on the recruitment of Yng1-associated complexes. Yng1 clearly mediates NuA3 association with nucleosomes (Howe et al. 2002), but why is H3K36 methylation the major determinant for its chromatin association? Moreover, the $\mathrm{HAT}$ activity associated with $\mathrm{NuA} 3$ purified from yeast was not stimulated by peptides containing H3K4me2 (Pray-Grant et al. 2005). Both H3K4 and H3K36 residues appear to be important for NuA3 function in vivo, although the mechanism remains unclear (Martin et al. 2006). How does Yng1 binding to H3K4me $2 / 3$ impact its biological activity if not through physical recruitment or HAT activity? The answer to this question will undoubtedly reveal insight into how all methyl-lysine "readers" communicate their downstream events and uncover important relationships between distinct lysine methyl marks (namely, H3K4 and H3K36).

Up to this point, we have discussed the specific recognition of $\mathrm{H} 3 \mathrm{~K} 4 \mathrm{me}$ via aromatic caging. This mode of specificity is not limited to H3K4 methylation, but also 
extends to all known methyl-ammonium-recognizing proteins described to date with the exception of one protein, WDR5. In addition, all factors that use aromatic caging to bind methyl-lysine residues do not display any appreciable interactions with the unmodified state. The WD40 repeat-domain containing protein WDR5 was reported to selectively recognize $\mathrm{H} 3 \mathrm{~K} 4 \mathrm{me} 2 / 3$, with a strong preference for H3K4me2 (Wysocka et al. 2005). WDR5 is a stable component of multiple HKMT complexes that specifically target H3K4 (Wysocka et al. 2003; Tenney and Shilatifard 2005). The WD40 repeat is present in hundreds of proteins with diverse nuclear and cytoplasmic functions. It was proposed that WDR5 binding to $\mathrm{H} 3 \mathrm{~K} 4 \mathrm{me} 2$ serves to convert $\mathrm{H} 3 \mathrm{~K} 4 \mathrm{me} 2$ to H3K4me3 by the MLL complex that harbors both WDR5 and the HKMT; this would then lead to methylation spreading (Wysocka et al. 2005). The initial data that support the notion that WDR5 selectively and directly binds $\mathrm{H} 3 \mathrm{~K} 4 \mathrm{me} 2 / 3$ were based on peptide affinity precipitation assays (Wysocka et al. 2005). However, a recent collection of structural and quantitative studies indicates that WDR5 binding to the $\mathrm{H} 3$ tail is significant independent of the level of H3K4 methylation (Couture et al. 2006b; Han et al. 2006; Ruthenburg et al. 2006). First, the binding characteristics of WDR5 to various H3 tail peptides were examined using surface plasmon resonance. These quantitative analyses revealed that WDR5 binds to the four states of $\mathrm{H} 3 \mathrm{~K} 4(\mathrm{me} 0 / 1 / 2 / 3)$ with values comparable to $\mathrm{H} 3 \mathrm{~K} 4 \mathrm{me} 2 / 3$ binding by BPTF, hCHD1, JMJD2A, and the ING family (Table 1; Ruthenburg et al. 2006). It was reported in this study that WDR5 binds to $\mathrm{H} 3 \mathrm{~K} 4 \mathrm{me} 2$ with a threefold higher affinity than $\mathrm{H} 3 \mathrm{~K} 4 \mathrm{me} 0(\sim 1.0 \mu \mathrm{M}$ and $3.3 \mu \mathrm{M}$, respectively) (Table 1). This is in contrast to WDR5 binding to H3K4me1 and H3K4me3, which was reported to be weaker than to the unmodified peptide (Table 1). Is the threefold higher affinity for H3K4me2 compared with the unmodified peptide significant? An independent study using isothermal titration calorimetry suggests not, as WDR5 was observed to bind to all forms of H3K4 with equal affinities (Table 1; Couture et al. 2006b). In general, isothermal titration calorimetry (ITC) is a more reliable method than surface plasmon resonance (SPR) for calculating equilibrium dissociation constants. SPR does not directly measure equilibrium dissociation constants as it is a kinetic-binding assay, compared with ITC, which is an equilibrium-binding assay. Moreover, the use of SPR has contributed to the inaccurate calculation of equilibrium dissociation constants for factors that recognize methylated histone tails (1000-fold off) (Bannister et al. 2001). In general, the reported variations of equilibrium dissociation constants $(\sim 1-10 \mu \mathrm{M})$ of methyl-binding factors make speculation with respect to specificity more difficult. Therefore, claims for "high specificity" of a particular methyl state are more appropriate after exhaustive analyses using multiple techniques. The kinetic analyses do suggest that WDR5 binding to H3K4me2 occurs more slowly relative to that of the other H3K4 peptides, although once bound, H3K4me2 remains associated with WDR5 for a longer time; this might be a clue as to the detailed role of WDR5 binding to the H3 tail. In any case, both analyses demonstrate that WDR5 binds to all forms of H3K4 with comparable affinities (Table 1; Couture et al. 2006b; Ruthenburg et al. 2006).

What defines selective methyl-lysine recognition? We propose that factors considered specific "readers" of methyl-lysine residues should not display appreciable recognition of the unmodified state. WDR 5 is the only factor discussed herein to display interactions with H3K4me0 ( 3-7 $\mu \mathrm{M})$ (Table 1). What do the structural analyses of WDR5 binding to H3K4me suggest? Three separate studies clearly determine the mode of WDR5 binding to the $\mathrm{N}$-terminal tail of histone $\mathrm{H} 3$ (Couture et al. 2006b; Han et al. 2006; Ruthenburg et al. 2006). Arg 2 of the $\mathrm{H} 3$ tail appears to be the major determinant for WDR5 binding, a feature that is consistent between the three studies. In contrast, no consistent determinants were reported between the three studies that would indicate a mode for methyl-specificity. One structure indicated that the H3K4 side chain made no appreciable contacts with WDR5 and was solvent exposed (Fig. 1; Couture et al. 2006b; Han et al. 2006; Ruthenburg et al. 2006). The two additional solved structures indicate some H3K4-methyl contact, although the nature of the methyl recognition was not the same, and did not indicate a clear mode for $\mathrm{H} 3 \mathrm{~K} 4 \mathrm{me} 2$ specificity. In sum, the quantitative and structural analyses discussed herein do not support the notion that WDR5 is a preferential H3K4me-binding protein. It is highly probable that WDR5 is an essential component for histone tail presentation required for subsequent $\mathrm{H} 3 \mathrm{~K} 4$ methylation, although without specificity for the methylated or nonmethylated state. This notion is supported by functional studies, which indicate that a point mutation in WDR5 that reduces histone tail binding significantly impairs all levels of methylation of H3K4 by MLL (Dou et al. 2006).

\section{Functional considerations}

Within the past year, we have learned that three distinct protein domains selectively recognize $\mathrm{H} 3 \mathrm{~K} 4 \mathrm{me}$ : the tandem chromodomains of hCHD1, the double Tudor domains of JMJD2A, and the PHD fingers of BPTF and the ING family. These findings will likely provide the necessary framework to tackle important questions regarding the mechanistic readout of histone tail modifications. Future studies directed toward addressing the mechanism of $\mathrm{H} 3 \mathrm{~K} 4 \mathrm{me}$ recognition will require in vitro assays that can distinguish direct from indirect effects. The dissociation constants described for the various $\mathrm{H} 3 \mathrm{~K} 4 \mathrm{me}$-binding proteins fall in the $1-10 \mu \mathrm{M}$ range, values identical to $\mathrm{HP} 1$ and PC binding to repressive methyl-lysine marks. Since HP1 binding to chromatin is highly dynamic, binding to H3K4 will likely be so, especially considering the active process of transcription. In addition, methyl-lysine binding cannot impart specificity on its own, as numerous factors can bind to the same H3K4me mark. For example, what signals hCHD1 binding to $\mathrm{H} 3 \mathrm{~K} 4 \mathrm{me} 2 / 3$, as opposed to any of the other H3K4me readers? Several possibilities exist, and deci- 
A

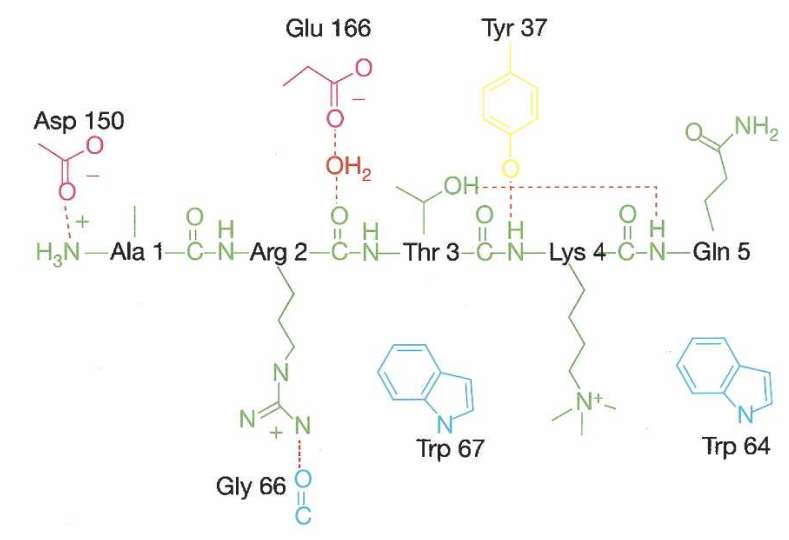

B

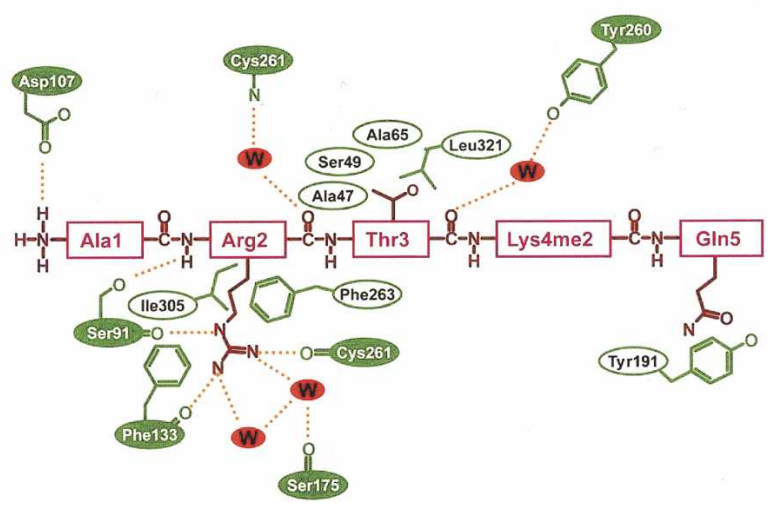

Figure 1. Differences in determinants of the recognition of histone $\mathrm{H} 3$ tail residues 1-5. (A) Recognition of the Lys 4-methylated $\mathrm{H} 3$ tail by human $\mathrm{CHD} 1$ requires chromodomain 1 (cyan) and chromodomain 2 (magenta) residues. Tryptophans form pication interactions with methyl-Lys 4 and Arg 2. Formation of a similar aromatic cage surrounding methyl-Lys 4 is also observed for the double Tudor domains of JMJD2A and the PHD fingers of ING2 and BPTF. Hydrogen bonds are indicated by red dotted lines. Figure adapted with permission from Macmillan Publishers Ltd.: Nature (Flanagan et al. 2005) (C 2005 [http:// www.nature.com]). (B) Schematic of the structural determinants of WDR5 recognition of the H3K4me2 peptide is shown. Hydrogen bonds and salt bridges are indicated by orange dotted lines; van der Waals contacts are also displayed. Figure and legend adapted with permission from Macmillan Publishers Ltd.: Nature Structural and Molecular Biology (Couture et al. 2006b) (C) 2006 [http://www.nature.com]).

phering this layer of complexity is necessary to fully understand the impact of histone methylation in gene regulation. Since histone acetylation is directly affected by histone methylation in some instances (Kouskouti and Talianidis 2005; Pray-Grant et al. 2005), histone methylation may serve to target and stimulate enzymatic activities at specific chromatin regions. This idea is also supported by H3K36-mediated recruitment of Eaf3 in yeast, which subsequently targets histone deacetylation within the coding regions of active genes (Carrozza et al. 2005; Joshi and Struhl 2005; Keogh et al. 2005). Does H3K4me similarly regulate CHD1 and NURF-mediated chromatin remodeling? If so, this regulation is likely complex, as ISWI, the ATPase of NURF, is stimulated by $\mathrm{H} 4$ tails and is modulated by histone acetylation (Clapier et al. 2002). With the findings discussed herein as a beginning, we can look forward to exciting discoveries that are certain to decipher the functional consequences of histone methylation during active transcription.

\section{Acknowledgments}

We thank Drs. A. Ruthenburg, R. Roeder, R. Trievel, and G. Verdine for providing their manuscripts prior to publication, and Drs. D. Allis, S. Gamblin, M. Hampsey, S. Khorasanizadeh, S. Patel, A. Ruthenburg, A. Shatkin, A. Shilatifard, R. Trievel, P. Trojer, L. Vales, J. Workman, and J. Wysocka for critical reading and comments on the manuscript. We especially thank S. Gamblin, S. Khorasanizadeh, S. Patel, and R. Trievel for critical discussions and comments regarding structural and quantitative aspects of binding to H3K4. D.R. and R.J.S. are supported by the HHMI (D.R.) and grants from the NIH (GM-37120 to D.R., GM71166 to R.J.S.).

\section{References}

Badenhorst, P., Xiao, H., Cherbas, L., Kwon, S.Y., Voas, M., Rebay, I., Cherbas, P., and Wu, C. 2005. The Drosophila nucleosome remodeling factor NURF is required for Ecdysteroid signaling and metamorphosis. Genes \& Dev. 19: 2540-2545.

Bannister, A.J. and Kouzarides, T. 2005. Reversing histone methylation. Nature 436: 1103-1106.

Bannister, A.J., Zegerman, P., Partridge, J.F., Miska, E.A., Thomas, J.O., Allshire, R.C., and Kouzarides, T. 2001. Selective recognition of methylated lysine 9 on histone $\mathrm{H} 3$ by the HP1 chromo domain. Nature 410: 120-124.

Bannister, A.J., Schneider, R., and Kouzarides, T. 2002. Histone methylation: Dynamic or static? Cell 109: 801-806.

Bernstein, B.E., Kamal, M., Lindblad-Toh, K., Bekiranov, S., Bailey, D.K., Huebert, D.J., McMahon, S., Karlsson, E.K., Kulbokas III, E.J., Gingeras, T.R., et al. 2005. Genomic maps and comparative analysis of histone modifications in human and mouse. Cell 120: 169-181.

Carrozza, M.J., Li, B., Florens, L., Suganuma, T., Swanson, S.K., Lee, K.K., Shia, W.J., Anderson, S., Yates, J., Washburn, M.P., et al. 2005. Histone $\mathrm{H} 3$ methylation by Set2 directs deacetylation of coding regions by $\mathrm{Rpd} 3 \mathrm{~S}$ to suppress spurious intragenic transcription. Cell 123: 581-592.

Clapier, C.R., Nightingale, K.P., and Becker, P.B. 2002. A critical epitope for substrate recognition by the nucleosome remodeling ATPase ISWI. Nucleic Acids Res. 30: 649-655.

Couture, J.F., Collazo, E., Hauk, G., and Trievel, R.C. 2006a. Structural basis for the methylation site specificity of SET7/ 9. Nat. Struct. Mol. Biol. 13: 140-146.

Couture, J.-F., Collazo, E., and Trievel, R.C. 2006b. Molecular recognition of histone $\mathrm{H} 3$ by the WD40 protein WDR5. Nat. Struct. Mol. Biol. 13: 698-703.

Dou, Y., Milne, T.A., Ruthenburg, A.J., Lee, S., Lee, J.W., Verdine, G.L., Allis, C.D., and Roeder, R.G. 2006. Regulation of MLL1 H3 K4 methyltransferase activity by its core components. Nat. Struct. Mol. Biol. 13: 713-719.

Dover, J., Schneider, J., Tawiah-Boateng, M.A., Wood, A., Dean, K., Johnston, M., and Shilatifard, A. 2002. Methylation of histone $\mathrm{H} 3$ by COMPASS requires ubiquitination of histone H2B by Rad6. J. Biol. Chem. 277: 28368-28371. 
Doyon, Y., Cayrou, C., Ullah, M., Landry, A.J., Cote, V., Selleck, W., Lane, W.S., Tan, S., Yang, X.J., and Cote, J. 2006. ING tumor suppressor proteins are critical regulators of chromatin acetylation required for genome expression and perpetuation. Mol. Cell 21: 51-64.

Fischle, W., Wang, Y., Jacobs, S.A., Kim, Y., Allis, C.D., and Khorasanizadeh, S. 2003. Molecular basis for the discrimination of repressive methyl-lysine marks in histone $\mathrm{H} 3$ by Polycomb and HP1 chromodomains. Genes \& Dev. 17: $1870-1881$.

Flanagan, J.F., Mi, L.Z., Chruszcz, M., Cymborowski, M., Clines, K.L., Kim, Y., Minor, W., Rastinejad, F., and Khorasanizadeh, S. 2005. Double chromodomains cooperate to recognize the methylated histone H3 tail. Nature 438: 11811185.

Han, Z., Guo, L., Wang, H., Shen, Y., Deng, X.W., and Chai, J. 2006. Structural basis for the specific recognition of methylated histone $\mathrm{H} 3$ lysine 4 by the WD-40 protein WDR5. Mol. Cell 22: 137-144.

Henry, K.W., Wyce, A., Lo, W.S., Duggan, L.J., Emre, N.C., Kao, C.F., Pillus, L., Shilatifard, A., Osley, M.A., and Berger, S.L. 2003. Transcriptional activation via sequential histone $\mathrm{H} 2 \mathrm{~B}$ ubiquitylation and deubiquitylation, mediated by SAGA-associated Ubp8. Genes \& Dev. 17: 2648-2663.

Howe, L., Kusch, T., Muster, N., Chaterii, R., Yates III, J.R., and Workman, J.L. 2002. Yng1p modulates the activity of Sas3p as a component of the yeast NuA3 histone acetyltransferase complex. Mol. Cell. Biol. 22: 5047-5053.

Huang, Y., Fang, J., Bedford, M.T., Zhang, Y., and Xu, R.M. 2006. Recognition of histone $\mathrm{H} 3$ lysine- 4 methylation by the double tudor domain of JMJD2A. Science 312: 748-751.

Jacobs, S.A. and Khorasanizadeh, S. 2002. Structure of HP1 chromodomain bound to a lysine 9-methylated histone H3 tail. Science 295: 2080-2083.

Joshi, A.A. and Struhl, K. 2005. Eaf3 chromodomain interaction with methylated H3-K36 links histone deacetylation to Pol II elongation. Mol. Cell 20: 971-978.

Keogh, M.C., Kurdistani, S.K., Morris, S.A., Ahn, S.H., Podolny, V., Collins, S.R., Schuldiner, M., Chin, K., Punna, T., Thompson, N.J., et al. 2005. Cotranscriptional set2 methylation of histone $\mathrm{H} 3$ lysine 36 recruits a repressive $\mathrm{Rpd} 3 \mathrm{com}$ plex. Cell 123: 593-605.

Kim, J., Daniel, J., Espejo, A., Lake, A., Krishna, M., Xia, L., Zhang, Y., and Bedford, M.T. 2006. Tudor, MBT and chromo domains gauge the degree of lysine methylation. EMBO Rep. 7: 397-403.

Kouskouti, A. and Talianidis, I. 2005. Histone modifications defining active genes persist after transcriptional and mitotic inactivation. EMBO J. 24: 347-357.

Kouskouti, A., Scheer, E., Staub, A., Tora, L., and Talianidis, I. 2004. Gene-specific modulation of TAF10 function by SET9mediated methylation. Mol. Cell 14: 175-182.

Lachner, M., O'Carroll, D., Rea, S., Mechtler, K., and Jenuwein, T. 2001. Methylation of histone $\mathrm{H} 3$ lysine 9 creates a binding site for HP1 proteins. Nature 410: 116-120.

Li, H., Ilin, S., Wang, W., Duncan, E.M., Wysocka, J., Allis, C.D., and Patel, D.J. 2006. Molecular basis for site-specific readout of histone H3K4me3 by the BPTF PHD finger of NURF. Nature 442: 91-95.

Lusser, A., Urwin, D.L., and Kadonaga, J.T. 2005. Distinct activities of CHD1 and ACF in ATP-dependent chromatin assembly. Nat. Struct. Mol. Biol. 12: 160-166.

Margueron, R., Trojer, P., and Reinberg, D. 2005. The key to development: Interpreting the histone code? Curr. Opin. Genet. Dev. 15: 163-176.

Martin, C. and Zhang, Y. 2005. The diverse functions of histone lysine methylation. Nat. Rev. Mol. Cell Biol. 6: 838-849.

Martin, D.G., Grimes, D.E., Baetz, K., and Howe, L. 2006. Methylation of histone $\mathrm{H} 3$ mediates the association of the $\mathrm{NuA} 3$ histone acetyltransferase with chromatin. Mol. Cell. Biol. 26: 3018-3028.

Maurer-Stroh, S., Dickens, N.J., Hughes-Davies, L., Kouzarides, T., Eisenhaber, F., and Ponting, C.P. 2003. The Tudor domain 'Royal Family': Tudor, plant Agenet, Chromo, PWWP and MBT domains. Trends Biochem. Sci. 28: 69-74.

Mizuguchi, G., Tsukiyama, T., Wisniewski, J., and Wu, C. 1997. Role of nucleosome remodeling factor NURF in transcriptional activation of chromatin. Mol. Cell 1: 141-150.

Nielsen, P.R., Nietlispach, D., Mott, H.R., Callaghan, J., Bannister, A., Kouzarides, T., Murzin, A.G., Murzina, N.V., and Laue, E.D. 2002. Structure of the HP1 chromodomain bound to histone H3 methylated at lysine 9. Nature 416: 103-107.

Nourani, A., Doyon, Y., Utley, R.T., Allard, S., Lane, W.S., and Cote, J. 2001. Role of an ING1 growth regulator in transcriptional activation and targeted histone acetylation by the NuA4 complex. Mol. Cell. Biol. 21: 7629-7640.

Nourani, A., Howe, L., Pray-Grant, M.G., Workman, J.L., Grant, P.A., and Cote, J. 2003. Opposite role of yeast ING family members in p53-dependent transcriptional activation. $J$. Biol. Chem. 278: 19171-19175.

Pavri, R., Zhu, B., Li, G., Trojer, P., Mandal, S., Shilatifard, A., and Reinberg, D. 2006. Histone H2B monoubiquitination functions cooperatively with FACT to regulate elongation by RNA polymerase II. Cell 125: 703-717.

Pena, P.V., Davrazou, F., Shi, X., Walter, K.L., Verkhusha, V.V., Gozani, O., Zhao, R., and Kutateladze, T.G. 2006. Molecular mechanism of histone $\mathrm{H} 3 \mathrm{~K} 4 \mathrm{me} 3$ recognition by plant homeodomain of ING2. Nature 442: 100-103.

Pray-Grant, M.G., Daniel, J.A., Schieltz, D., Yates III, J.R., and Grant, P.A. 2005. Chd1 chromodomain links histone H3 methylation with SAGA- and SLIK-dependent acetylation. Nature 433: 434-438.

Ruthenburg, A.J., Wang, W., Graybosch, D.M., Li, H., Allis, C.D., Patel, D.J., and Verdine, G.L. 2006. Histone H3 recognition and presentation by the WDR5 module of the MLL1 complex. Nat. Struct. Mol. Biol. 13: 704-712.

Sanders, S.L., Portoso, M., Mata, J., Bahler, J., Allshire, R.C., and Kouzarides, T. 2004. Methylation of histone H4 lysine 20 controls recruitment of $\mathrm{Crb} 2$ to sites of DNA damage. Cell 119: 603-614.

Schneider, R., Bannister, A.J., and Kouzarides, T. 2002. Unsafe SETs: Histone lysine methyltransferases and cancer. Trends Biochem. Sci. 27: 396-402.

Schneider, R., Bannister, A.J., Myers, F.A., Thorne, A.W., CraneRobinson, C., and Kouzarides, T. 2004. Histone H3 lysine 4 methylation patterns in higher eukaryotic genes. Nat. Cell Biol. 6: 73-77.

Schotta, G., Lachner, M., Sarma, K., Ebert, A., Sengupta, R., Reuter, G., Reinberg, D., and Jenuwein, T. 2004. A silencing pathway to induce $\mathrm{H} 3-\mathrm{K} 9$ and $\mathrm{H} 4-\mathrm{K} 20$ trimethylation at constitutive heterochromatin. Genes \& Dev. 18: 1251-1262.

Shi, X., Hong, T., Walter, K.L., Ewalt, M., Michishita, E., Hung, T., Carney, D., Pena, P., Lan, F., Kaadige, M.R., et al. 2006. ING2 PHD domain links histone H3 lysine 4 methylation to active gene repression. Nature 442: 96-99.

Shilatifard, A. 2006. Chromatin modifications by methylation and ubiquitination: Implications in the regulation of gene expression. Annu. Rev. Biochem. 75: 243-269.

Sims III, R.J., Nishioka, K., and Reinberg, D. 2003. Histone lysine methylation: A signature for chromatin function. Trends Genet. 19: 629-639.

Sims III, R.J., Belotserkovskaya, R., and Reinberg, D. 2004. Elon- 
gation by RNA polymerase II: The short and long of it. Genes \& Dev. 18: 2437-2468.

Sims III, R.J., Chen, C.F., Santos-Rosa, H., Kouzarides, T., Patel, S.S., and Reinberg, D. 2005. Human but not yeast CHD1 binds directly and selectively to histone $\mathrm{H} 3$ methylated at lysine 4 via its tandem chromodomains. J. Biol. Chem. 280: 41789-41792.

Smith, S.T., Petruk, S., Sedkov, Y., Cho, E., Tillib, S., Canaani, E., and Mazo, A. 2004. Modulation of heat shock gene expression by the TAC1 chromatin-modifying complex. Nat. Cell Biol. 6: 162-167.

Strahl, B.D. and Allis, C.D. 2000. The language of covalent histone modifications. Nature 403: 41-45.

Sun, Z.W. and Allis, C.D. 2002. Ubiquitination of histone H2B regulates $\mathrm{H} 3$ methylation and gene silencing in yeast. $\mathrm{Na}$ ture 418: 104-108.

Tenney, K. and Shilatifard, A. 2005. A COMPASS in the voyage of defining the role of trithorax/MLL-containing complexes: Linking leukemogenesis to covalent modifications of chromatin. J. Cell. Biochem. 95: 429-436.

Trojer, P. and Reinberg, D. 2006. Histone lysine demethylases and their impact on epigenetics. Cell 125: 213-217.

Turner, B.M. 2000. Histone acetylation and an epigenetic code. Bioessays 22: 836-845.

Wysocka, J., Myers, M.P., Laherty, C.D., Eisenman, R.N., and Herr, W. 2003. Human Sin3 deacetylase and trithorax-related Set1/Ash2 histone H3-K4 methyltransferase are tethered together selectively by the cell-proliferation factor HCF-1. Genes \& Dev. 17: 896-911.

Wysocka, J., Swigut, T., Milne, T.A., Dou, Y., Zhang, X., Burlingame, A.L., Roeder, R.G., Brivanlou, A.H., and Allis, C.D. 2005. WDR5 associates with histone $\mathrm{H} 3$ methylated at K4 and is essential for H3 K4 methylation and vertebrate development. Cell 121: 859-872.

Wysocka, J., Swigut, T., Xiao, H., Milne, T.A., Kwon, S.Y., Landry, J., Kauer, M., Tackett, A.J., Chait, B.T., Badenhorst, P., et al. 2006. A PHD finger of NURF couples histone H3 lysine 4 trimethylation with chromatin remodelling. Nature 442: $86-90$.

Xiao, H., Sandaltzopoulos, R., Wang, H.M., Hamiche, A., Ranallo, R., Lee, K.M., Fu, D., and Wu, C. 2001. Dual functions of largest NURF subunit NURF301 in nucleosome sliding and transcription factor interactions. Mol. Cell 8: 531543.

Xiao, B., Jing, C., Wilson, J.R., Walker, P.A., Vasisht, N., Kelly, G., Howell, S., Taylor, I.A., Blackburn, G.M., and Gamblin, S.J. 2003. Structure and catalytic mechanism of the human histone methyltransferase SET7/9. Nature 421: 652-656. 


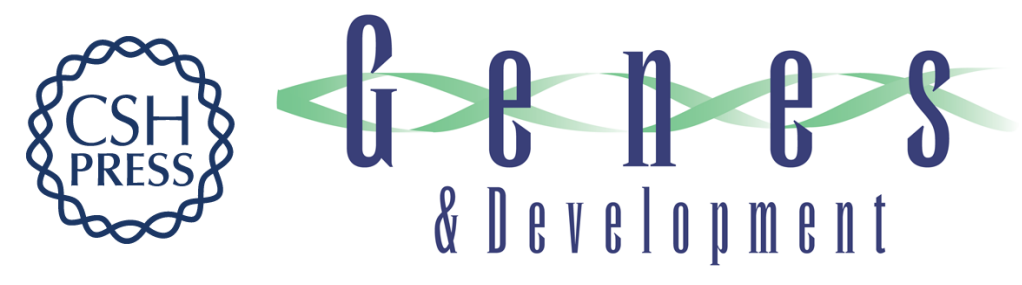

\section{Histone H3 Lys 4 methylation: caught in a bind?}

Robert J. Sims III and Danny Reinberg

Genes Dev. 2006, 20:

Access the most recent version at doi:10.1101/gad.1468206

Related Content The Drosophila nucleosome remodeling factor NURF is required for Ecdysteroid signaling and metamorphosis

Paul Badenhorst, Hua Xiao, Lucy Cherbas, et al.

Genes Dev. November, 2005 19: 2540-2545 A silencing pathway to induce H3-K9 and

H4-K20 trimethylation at constitutive heterochromatin

Gunnar Schotta, Monika Lachner, Kavitha Sarma, et al.

Genes Dev. June , 2004 18: 1251-1262 Transcriptional activation via sequential histone H2B ubiquitylation and deubiquitylation, mediated by SAGA-associated Ubp8

Karl W. Henry, Anastasia Wyce, Wan-Sheng Lo, et al.

Genes Dev. November , 2003 17: 2648-2663 Molecular basis for the discrimination of repressive methyl-lysine marks in histone $\mathrm{H} 3$ by Polycomb and HP1

chromodomains

Wolfgang Fischle, Yanming Wang, Steven A. Jacobs, et al.

Genes Dev. August , 2003 17: 1870-1881 Jmjd1a and Jmjd2c histone H3 Lys 9

demethylases regulate self-renewal in embryonic stem cells

Yuin-Han Loh, Weiwei Zhang, Xi Chen, et al.

Genes Dev. October , 2007 21: 2545-2557

References This article cites 59 articles, 15 of which can be accessed free at:

http://genesdev.cshlp.org/content/20/20/2779.full.html\#ref-list-1

Articles cited in:

http://genesdev.cshlp.org/content/20/20/2779.full.html\#related-urls

License

Email Alerting Receive free email alerts when new articles cite this article - sign up in the box at the top Service right corner of the article or click here.

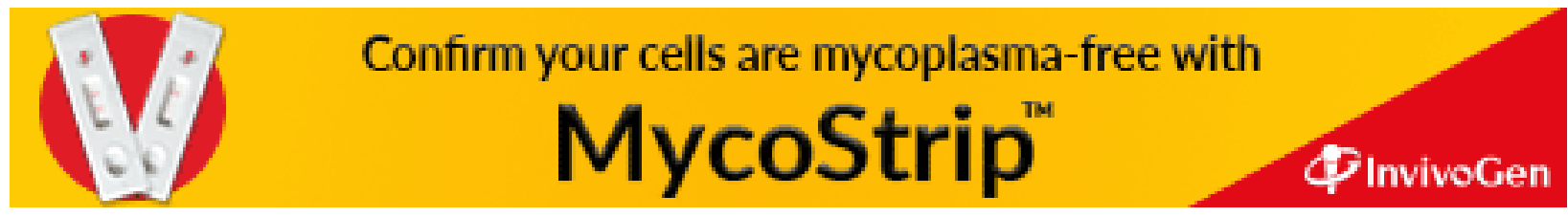

